\title{
Orfebrería precolombina: categorías de análisis en las tesis de la Escuela de Artes Plásticas (1953-1977)
}

\author{
Pre-Columbian Goldsmithing: \\ Categories of Analysis in the Theses of \\ the School of Plastic Arts (1953-1977)
}

Ana Catalina Lizano Quesada

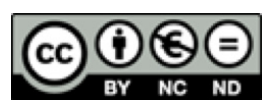

Esta obra está bajo una licencia Creative Commons Reconocimiento-No comercial-Sin Obra Derivada 


\section{Orfebrería Precolombina: categorías de análisis en las tesis de la Escuela de Artes Plásticas (1953-1977) \\ Pre-Columbian Goldsmithing: \\ Categories of Analysis in the Theses of the School of Plastic Arts (1953-1977)

\author{
Ana Catalina Lizano Quesada ${ }^{1}$ \\ Universidad de Costa Rica \\ Costa Rica
}

Recibido: 22 de octubre de 2018 Aprobado: 19 de noviembre de 2018

\section{Resumen}

En la Universidad de Costa Rica, la orfebrería precolombina ha sido explorada desde diversos campos, entre ellos, la arqueología, la historia, la identidad cultural, la arquitectura y arte. El presente estudio persigue reconstruir el conocimiento generado, de forma exclusiva, a partir de las tesis realizadas en la Escuela de Artes Plásticas. Se revelan las categorías de análisis utilizadas por los investigadores y se examinan las variantes encontradas en el abordaje del objeto de estudio. Se presentan datos contextuales sobre esta práctica en la Escuela de Artes Plásticas. En cuanto al estado actual de la especialidad, se desarrollan algunas reflexiones en torno a la vigencia de la orfebrería en esta institución y sus alcances.

Palabras clave: Arte Precolombino; Orfebrería costarricense; Metalurgia; Oro; Historiografía

\section{Abstract}

At the University of Costa Rica pre-Columbian goldsmithing has been explored from different fields, including archeology, history, cultural identity, architecture and art. The present study seeks to reconstruct the knowledge generated, exclusively, from the theses made in the School of Plastic Arts. The categories of analysis used by the researchers are revealed and the variants found in the approach of the object of study are examined. We present contextual data about this practice at the School of Plastic Arts and on the current state of the specialty, some reflections are developed around the validity of goldsmithing in this institution and its scope.

Keywords: Pre-Columbian; Costa Rican Goldsmithing; Metallurgy; Gold; Historiography

1 Estudiante de la Maestría Académica en Artes Visuales. Bachiller en Artes Plásticas, con énfasis en Artes Gráficas. Correo electrónico: catalina.lizanoquesada@ucr.ac.cr 
Orfebrería precolombina:categorías de análisis en las tesis

Dossier de la Escuela de Artes Plásticas (1953-1977)

\section{Introducción}

La colección de orfebrería precolombina costarricense ha sido estudiada ampliamente. La posibilidad de obtener conocimiento sobre el mundo indígena suscita asombro e interés, principalmente, cuando se concreta en restos materiales fabricados en metales preciosos. En la Universidad de Costa Rica (UCR), la producción académica sobre el tema precolombino contempla estudios en Arqueología, Arquitectura, identidad cultural e Historia. Así, las cualidades formales, técnicas, materiales, contextuales y espacio-temporales de los objetos son enfatizadas según sea el interés de su autor. Desde la perspectiva del arte, se realizaron investigaciones en las que la mirada se sitúa en aspectos que amplían la lectura de tales objetos. Es notoria la influencia del método utilizado en arqueología en la descripción de piezas antiguas, un rasgo común en las investigaciones sobre arte precolombino, independientemente del enfoque de los autores.

Se encontró un total de quince tesis sobre el tema, en la base de datos de la Biblioteca Francisco Amighetti, de las cuales, solo cinco incluyeron la orfebrería dentro de los grupos de objetos a analizar. Se trata de un corpus reducido, generado entre los años 1953 y 1977. A partir de estas cinco tesis realizadas en la Escuela de Artes Plásticas (EAP) de la UCR, se persigue develar los intereses de los investigadores en arte al estudiar la orfebrería precolombina. Para ello, se ha propuesto un estudio que permite identificar las categorías de análisis utilizadas al examinar los objetos y distinguir aspectos comunes o contrastes en los enfoques establecidos por los autores. De esta manera, es posible registrar la evolución de esa mirada sobre la orfebrería que se construyó durante el corto periodo de tiempo en que fue explorada, con mayor atención y frecuencia, en la EAP. Las tesis no tratan con exclusividad la producción orfebre precolombina, sino que analizan varios grupos de artefactos y las incorporan. Se ha desarrollado una serie de cuadros en los que se desglosan los aspectos destacados en cada tesis, así como los grupos de objetos referidos y sus características. Estos pueden ser revisados en el apartado de Anexos.

La documentación sobre orfebrería disponible en la Escuela de Artes Plásticas es muy limitada. Se tuvo acceso al archivo histórico de la Biblioteca Francisco Amighetti, el cual recoge los programas de estudio de la EAP, con el fin de revisar los indicios más antiguos de la especialidad, así como variaciones en los programas de los cursos de orfebrería. Aunque insuficiente, esta información ofreció una serie de datos que fueron complementados con dos 
entrevistas realizadas a los señores Luis Paulino Delgado ${ }^{2}$ y Herberth Zamora ${ }^{3}$, ambos docentes en la especialidad, ya acogidos a su jubilación.

\section{Las décadas de 1950 y 1960: la ruta hacia la orfebrería}

\section{María Eugenia Huertas (1953)}

La tesis más antigua encontrada en la Escuela de Artes Plásticas de la Universidad de Costa Rica se titula Arte Pre-Colombino en Costa Rica, realizada por María Eugenia Huertas en 1953. La autora investiga distintas tipologías de artefactos e incluye objetos en metal. De estilo ensayístico, su tesis describe la producción precolombina a partir de rasgos generales y visibles, producto de la incipiente teoría disponible para su estudio. Es un momento temprano de la investigación arqueológica, dado que su profesionalización inició años más tarde, cuando en 1975 se instauró la carrera de Arqueología en la UCR. La autora separa el contenido de la tesis en dos secciones.

En la primera, realiza una caracterización del arte precolombino de América, que denomina Arte Medioeval Americano, por su contemporaneidad con la Edad Media europea (siglos XV y XVI). Periodo en el cual, los españoles tuvieron contacto con las culturas originarias de América. Huertas incluye los trabajos en metal y enfatiza en la variedad de materiales presentes en las piezas precolombinas: oro, plata, estaño, cobre, mercurio, platino, plomo, hierro y aleaciones entre estos. Además, menciona la técnica de la cera perdida.

La segunda sección se titula Cultura Precolombina de Costa Rica y emplea el modelo histórico generado en el siglo XIX. Este establece la división cultural de las poblaciones indígenas en tres grupos, los únicos que conocieron los españoles durante el siglo XVI:

2 Luis Paulino Delgado es Profesor Emérito de la Escuela de Artes Plásticas y trabaja como asesor en Artes Visuales en la Vicerrectoría de Acción Social en Extensión Cultural, de la Universidad de Costa Rica. Fue Decano de la Facultad de Artes y Director de la Escuela de Artes Plásticas, Licenciado en Pintura, en Derecho y profesor de Segunda Enseñanza en Bellas Artes, de la Universidad de Costa Rica. Máster en Ciencias de la Educación con énfasis en Grabado y Orfebrería, por State University College at Buffalo (Nueva York). Impartió cursos de orfebrería en la Escuela de Artes Plásticas.

3 Herberth Zamora es Licenciado en Escultura y Master en Artes Visuales, por la Universidad de Costa Rica. Fue Coordinador de Administración, Director del Departamento de Artes y Letras y Subdirector en la Sede de Occidente, Universidad de Costa Rica. Fue Subdirector en la Escuela de Artes Plásticas y Director del Instituto de Investigaciones en Arte (IIARTE), Universidad de Costa Rica. Impartió cursos de orfebrería en la Escuela de Artes Plásticas. 
Orfebrería precolombina:categorías de análisis en las tesis de la Escuela de Artes Plásticas (1953-1977)

Bruncas, Chorotegas y Huetares, formulado por Anastasio Alfaro y promovido por Jorge Lines en las décadas de 1950 y 1960 (Corrales, 2003, p. 33). Aquí, la autora organiza, nuevamente, una división de los objetos precolombinos tomando como base el material. Denomina una de ellas como trabajos metálicos y hace referencia al uso del oro y el cobre como metales predominantes. Identifica cuatro técnicas: cera perdida, laminación, repujado y grabado, con breves descripciones sobre los procesos de manufactura. Introduce algunos elementos de diseño, figuras humanas, animales y geometrías simples, lo cual, no contempló en la sección anterior. También cita tres tipologías de objetos (Cuadro 1). 
Tabla 1. Arte Precolombino en Costa Rica, María Eugenia Huertas (1953)

\begin{tabular}{|c|c|c|c|c|}
\hline \multicolumn{5}{|c|}{ Sección 1. Arte Medioeval Americano } \\
\hline Tipo de producción & Materiales & Técnica & Estilo & Tipología de objetos \\
\hline \multicolumn{5}{|l|}{ Arquitectura } \\
\hline \multicolumn{5}{|l|}{ Escultura } \\
\hline \multicolumn{5}{|l|}{ Cerámica } \\
\hline \multicolumn{5}{|l|}{ Tejidos } \\
\hline \multirow{8}{*}{ Trabajos metálicos } & Oro & Cera Perdida & & \\
\hline & Plata & & & \\
\hline & Estaño & & & \\
\hline & Cobre & & & \\
\hline & Mercurio & & & \\
\hline & Platino & & & \\
\hline & Plomo & & & \\
\hline & Hierro & & & \\
\hline \multicolumn{5}{|l|}{ Jade y otras piedras } \\
\hline \multicolumn{5}{|l|}{ Murales y manuscritos } \\
\hline \multirow{5}{*}{ Artes aplicadas } & Madera & & & \\
\hline & Mosaico & & & \\
\hline & Trabajos en concha & & & \\
\hline & Tallado en hueso & & & \\
\hline & Trabajos en plumas & & & \\
\hline
\end{tabular}




\begin{tabular}{|c|c|c|c|c|}
\hline \multicolumn{5}{|c|}{ Sección 2. Cultura Precolombina de Costa Rica } \\
\hline Tipo de producción & Materiales & Técnica & Estilo & Tipología de objetos \\
\hline \multirow{10}{*}{ Cerámica } & & Policromada & & \\
\hline & & Chocolate & & \\
\hline & & Negra & & \\
\hline & & Amarillo-café & & \\
\hline & & Roja & & \\
\hline & & Formas modeladas & & \\
\hline & & Pintura decorativa & & \\
\hline & & Cerámica palmar & & \\
\hline & & Cerámica luna & & \\
\hline & & Cerámica nandaime & & \\
\hline \multirow{4}{*}{ Trabajos metálicos } & Oro & Cera perdida & Figuras humanas & Joyas \\
\hline & \multirow{3}{*}{ Cobre } & Laminación & Animales & Objetos de culto \\
\hline & & Repujado & Geometrías simples & Otros \\
\hline & & Grabado & & \\
\hline
\end{tabular}

Fuente: Elaboración propia. 
En esta tesis se emplea la noción de un arte puro, místico y de la belleza, con peso en la narración anecdótica y cronológica, rasgos propios de las metodologías y descripciones utilizadas en el arte costarricense durante este periodo (Solano, 2014, p.20). En resumen, el análisis de Huertas puntualiza en los aspectos visibles de los objetos y desarrolla apreciaciones personales sobre los posibles significados de los mismos. Manifiesta algunos rasgos de las descripciones arqueológicas, aunque no presenta el rigor de la disciplina.

En ese entonces, varias políticas públicas impulsaron la creación de fondos e instituciones destinadas a la recuperación, salvaguarda e investigación del patrimonio arqueológico en el país. Gómez (1984) sitúa los primeros esfuerzos en esta materia durante la administración del expresidente Rafael Ángel Calderón Guardia (1900-1970), en su gestión de 1940 a 1944. Señala que, en este periodo, se establece el Decreto sobre Control de la Explotación y Comercio de Reliquias Históricas, primer avance en la protección del patrimonio. Otro importante hecho, en esta misma línea, es la fundación del Museo del Oro del Banco Central. Obando (2008) destaca que el primer Museo del Banco Central de Costa Rica (BCCR) fue creado en el año 1950, bajo el nombre de "Museo Arqueológico y Numismático del BCCR" (p. 400). Su creación fue motivada por el interés en recuperar y adquirir objetos realizados en oro y preservar la riqueza arqueológica del país, evitar la exportación de ejemplares valiosos y mantenerlos en una colección especializada.

Cabe destacar que, durante la década de 1950, comienza a incorporarse el término etnohistoria en la antropología cultural, producto de las manifestaciones del indigenismo, el nacionalismo y la búsqueda del pasado para reafirmar la originalidad de los pueblos y su identidad. Lorandi (2012), señala que, desde las décadas de 1960 y 1970, los etnohistoriadores centraron su atención en la sociedad indígena prehispánica de los últimos siglos antes de la conquista, con el fin de reconstruir la estructura sociocultural de las poblaciones americanas, mediante la arqueología, las crónicas y los documentos coloniales. La forma de lograrlo fue a través del estudio de objetos arqueológicos recuperados de entierros y excavaciones, su difusión y valoración. Así, la fundación del Museo del Oro marcó un hito en favor de la etnohistoria costarricense, al preservar piezas de gran valor arqueológico que servían para el fortalecimiento de la identidad. A la vez, favorecía al BCCR en sus reservas, sobre todo, por la adquisición de objetos que aumentan de valor a través del tiempo. Esta política impulsó el crecimiento de la colección, la recuperación y protección del patrimonio arqueológico nacional y su establecimiento propició el interés posterior por esta obra. La fecha de la tesis de Huertas (1953) coincide con los primeros años de funcionamiento del museo.

En el año 1964, el arqueólogo costarricense Carlos Aguilar (1917-2008) llevó a cabo la primera catalogación de la colección del Museo del Oro del BCCR. De acuerdo con el Informe de la Secretaría General del BCCR de 1994, el aporte de Aguilar brindó 
datos actualizados que sirvieron para el montaje del nuevo Museo de Oro Precolombino, ubicado, entonces, en el noveno piso del BCCR. El registro arqueológico es detallado y contempla aspectos funcionales, tecnológicos, artísticos y tipológicos para 1864 unidades de objetos reunidos en ese entonces. Basado en las herramientas documentales de la arqueología, el estudio contempla rigor y organización en la documentación de las obras. En años posteriores, Aguilar desarrolló una publicación en conjunto con la UCR, en la cual compiló el resultado de esta catalogación, acompañado de fotografías y filminas.

Otra coyuntura importante es detallada por Corrales (2003), quien afirma que, durante la década de 1960, eran muy comunes las excavaciones de cementerios realizadas, especialmente, por arqueólogos extranjeros. Es conocida la investigación del arqueólogo estadounidense Kirkland Lothrop (1892-1965), quien por mediación de la también arqueóloga Doris Stone (1909-1994) recibió una invitación en el año 1963 para trabajar en las propiedades de la United Fruit Company, localizadas en la zona del Delta del Diquís. Lothrop publicó, ese mismo año, los resultados del estudio realizado en conjunto con Stone, titulado Archaeology of the Diquís Delta, Costa Rica. En este incluyó planos de los conjuntos de esferas de piedra con detalladas descripciones, observaciones de los materiales hallados y clasificaciones de los objetos, principalmente de cerámica y lítica. Así, los estudios de Lothrop (1963) en Diquís y la catalogación de Aguilar (1967) en orfebrería aplicaban los instrumentos de la arqueología para la documentación y registro de piezas de arte precolombino. La difusión de estos dos estudios influyó en las investigaciones posteriores realizadas en la EAP, lo cual se detallará en el segundo apartado

\section{Rodrigo Revollar (1968)}

Rodrigo Revollar realizó en 1968 una recopilación de conferencias de su autoría, titulada Cuatro conferencias sobre Historia del Arte. Tres de ellas refieren al arte precolombino: Historia de México Precolombino, Historia del Perú Precolombino e Historia de Costa Rica Precolombina. El documento se encuentra catalogado como tesis en la base de datos de la biblioteca Francisco Amighetti, aunque no registra esa denominación en portada. Además, no indica el nombre de los tutores y no presenta el empaste correspondiente. Sin embargo, el documento trata el tema de interés y especifica algunos aspectos de orfebrería, por lo cual, se incluyó en este corpus.

Revollar (1968) relaciona cada uno de los países, México, Perú y Costa Rica, con áreas culturales precolombinas y desarrolla una cronología sobre las poblaciones o grupos indígenas que ocuparon cada región. Este nuevo modelo histórico denominado áreas de influencia fue propuesto por la arqueóloga Doris Stone. Este modelo sitúa al sur de América Central como una zona receptiva pasiva y puente de paso de las poblaciones de Mesoamérica y la región andina (Corrales, 2003, p. 33). 
El autor registra seis grupos de objetos, entre ellos la orfebrería y, al igual que Huertas (1953), las descripciones contemplan aspectos formales, materiales y técnicas de fabricación. En algunos casos, refiere a la representación y a la simbología de los motivos. Aporta datos históricos, en los que destaca las culturas predominantes, según periodos y espacios geográficos específicos. Asimismo, menciona la orfebrería en algunos apartados, con descripciones cortas sobre métodos de fabricación, materiales y tipología para los objetos de oro: collares, colgantes, aretes, diademas, discos o platos y figuras. Incluye, también, dos tipos de gemas: el jade y la turquesa. Con respecto a los metales utilizados destaca el oro, cobre, plata, bronce y tumbaga (aleación de oro y cobre). En cuanto a la técnica incorpora martillado, grabado y fundición (Cuadro 2). 


\section{Tabla 2. Cuatro conferencias sobre Arte Precolombino, Rodrigo Revollar (1968)}

\begin{tabular}{|c|c|c|c|c|c|c|}
\hline \multicolumn{7}{|c|}{ Sección 1. Historia de México Precolombino } \\
\hline \multicolumn{7}{|c|}{ MÉXICO PRECOLOMBINO } \\
\hline Área Cultural & Grupo cultural & Tipo de producción & Materiales & Técnica & Elementos de diseño & Tipología \\
\hline \multirow{13}{*}{$\begin{array}{c}\text { Nuevo } \\
\text { Imperio Maya }\end{array}$} & \multirow{6}{*}{ Teotihuacán } & Arquitectura & Piedra & Policromada & Serpiente & Pirámides \\
\hline & & & & & Floral & \\
\hline & & & & & Dioses & \\
\hline & & Pintura & & Fresco & & \\
\hline & & Escultura & & & Jaguar & Máscaras \\
\hline & & & & & Tláloc & \\
\hline & \multirow{4}{*}{ Tolteca } & Escultura & Piedra & Bajorrelieve & Águila & Monumentos \\
\hline & & & & & Jaguar & Calendario \\
\hline & & & & & Coyote & \\
\hline & & & & & Guerrero & \\
\hline & \multirow{3}{*}{ Azteca } & Escultura & Gemas & Talla & Jaguar ocelote & Vaso corazones \\
\hline & & & & & Dioses & Pirámides \\
\hline & & Pintura & & & Dioses & Manuscritos \\
\hline \multirow{11}{*}{$\begin{array}{c}\text { Antiguo } \\
\text { Imperio Maya }\end{array}$} & & Cerámica & & & Dioses & Estatuillas \\
\hline & & Madera & & & & Tambores \\
\hline & & Mosaico & Jade & & & Máscaras \\
\hline & & & Turquesa & & & \\
\hline & \multirow{3}{*}{ Olmeca } & Escultura & Piedra & Talla & & Cabezas \\
\hline & & & Jade & & & Estatuillas \\
\hline & & & & & & Máscaras \\
\hline & \multirow{3}{*}{ Totonaca } & Arquitectura & & & Geométrico & Pirámides \\
\hline & & Escultura & Piedra & Grabado & & \\
\hline & & & & Pulido & & \\
\hline & Huateca & Escultura & Piedra & & & Estatuas \\
\hline
\end{tabular}




\begin{tabular}{|c|c|c|c|c|c|c|}
\hline \multicolumn{7}{|c|}{ Sección 1. Historia de México Precolombino } \\
\hline \multicolumn{7}{|c|}{ MÉXICO PRECOLOMBINO } \\
\hline Área Cultural & Grupo cultural & Tipo de producción & Materiales & Técnica & Elementos de diseño & Tipología \\
\hline \multirow{10}{*}{$\begin{array}{c}\text { Antiguo } \\
\text { Imperio Maya }\end{array}$} & \multirow{2}{*}{ Zapoteca } & Arquitectura & & & & Edificios \\
\hline & & & & & & Terrazas \\
\hline & \multirow{5}{*}{ Mixteca } & Pintura & & Fresco & & Manuscritos \\
\hline & & Orfebrería & Oro & & & Collares \\
\hline & & & Metales & & & Colgantes \\
\hline & & & Jade & & & Aretes \\
\hline & & & Turquesa & & & Diademas \\
\hline & \multirow{2}{*}{ Colima y Nayarit } & Cerámica & & & Danzarinas & \\
\hline & & & & & Vida cotidiana & \\
\hline & Tarascos & Escultura & & & Vida cotidiana & \\
\hline
\end{tabular}

\begin{tabular}{|c|c|c|c|c|c|c|}
\hline \multicolumn{7}{|c|}{ Sección 2. Historia de Perú Precolombino } \\
\hline \multicolumn{7}{|c|}{ PERÚ PRECOLOMBINO } \\
\hline Área Cultural & Grupo cultural & Tipo de producción & Materiales & Técnica & Elementos diseño & Tipología \\
\hline \multirow{10}{*}{ Pre-Incaicas } & \multirow{7}{*}{ Chavín } & Arquitectura & Piedra & & Felinos & Edificios \\
\hline & & & & & Cabezas humanas & Terrazas \\
\hline & & & & & & Rampas \\
\hline & & & & & & Escalinatas \\
\hline & & Escultura & Grabado & & Cabezas & \\
\hline & & Cerámica & & & Gato & \\
\hline & & Tejido & & & Gato & \\
\hline & \multirow{3}{*}{ Chupisnique } & Cerámica & & Monocroma & Felino & Vasijas con asa \\
\hline & & & & Relieve & & \\
\hline & & Orfebrería & Oro & & & \\
\hline
\end{tabular}


de la Escuela de Artes Plásticas (1953-1977)

\begin{tabular}{|c|c|c|c|c|c|c|}
\hline \multicolumn{7}{|c|}{ Sección 2. Historia de Perú Precolombino } \\
\hline \multicolumn{7}{|c|}{ PERÚ PRECOLOMBINO } \\
\hline Área Cultural & Grupo cultural & Tipo de producción & Materiales & Técnica & Elementos diseño & Tipología \\
\hline \multirow{27}{*}{ Pre-Incaicas } & \multirow{10}{*}{ Mochica } & Arquitectura & & & & Pirámides \\
\hline & & Orfebrería & & & & \\
\hline & & Talla en madera & & & & \\
\hline & & Escultura & & & Semi-humano & \\
\hline & & & & & Semi-animal & \\
\hline & & Cerámica & Engobe blanco & Pintura & Guerreros & Vasija con estribo \\
\hline & & & Engobe rojo & Relieve & Músicos & \\
\hline & & & Engobe negro & & Enfermos & \\
\hline & & & & & Guerreros orejones & \\
\hline & & Tejidos & & & & \\
\hline & \multirow{10}{*}{ Nazca } & Arquitectura & & & & Cementerios \\
\hline & & Cerámica & & Policromado & Plantas & \\
\hline & & & & Relieve & Animales & \\
\hline & & & & & Personajes & \\
\hline & & & & & Seres mixtos & \\
\hline & & Tejidos & Algodón & Bordado & & Mantos \\
\hline & & & Lana de vicuña & Tapicería & & Túnicas \\
\hline & & & & Tejido & & Ponchos \\
\hline & & Orfebrería & Oro & Martillado & & \\
\hline & & & & Grabado & & \\
\hline & \multirow{7}{*}{ Tihuanaco } & Cerámica & & & Geométrico & Vasos \\
\hline & & & & & Felino & \\
\hline & & Arquitectura & Piedra & Talla & Dioses & Monolitos \\
\hline & & & & & Felino & \\
\hline & & & & & Serpiente & \\
\hline & & & & & Cóndor & \\
\hline & & Escultura & Piedra & & & Monumentos \\
\hline
\end{tabular}




\begin{tabular}{|c|c|c|c|c|c|c|}
\hline \multicolumn{7}{|c|}{ Sección 2. Historia de Perú Precolombino } \\
\hline \multicolumn{7}{|c|}{ PERÚ PRECOLOMBINO } \\
\hline Área Cultural & Grupo cultural & Tipo de producción & Materiales & Técnica & Elementos diseño & Tipología \\
\hline \multirow{10}{*}{ Pre-Incaicas } & \multirow{10}{*}{ Chimú } & Arquitectura & & & & Adobe \\
\hline & & Cerámica & Cerámica negra & & & Vaso doble \\
\hline & & & Monocromo & & & \\
\hline & & & Relieve & & & \\
\hline & & Escultura & Piedra & & Dioses & \\
\hline & & Orfebrería & Cobre & & & Vasos \\
\hline & & & Bronce & & & \\
\hline & & & Oro & & & \\
\hline & & & Plata & & & \\
\hline & & & Tumbaga & & & \\
\hline \multirow{9}{*}{ Incaicas } & & Arquitectura & Piedra & & & Monumentos \\
\hline & & & & & & Templos \\
\hline & & & & & & Fortalezas \\
\hline & & & & & & Puerta trapezoide \\
\hline & & Cerámica & & Relieve & Puma & Aríbalo dos asas \\
\hline & & Madera & Madera & Policromado & & Vaso Kero \\
\hline & & Orfebrería & & Incrustación & & \\
\hline & & Tejidos & Algodón & & & Tapicería \\
\hline & & & Lana de llama & & & \\
\hline
\end{tabular}


de la Escuela de Artes Plásticas (1953-1977)

\begin{tabular}{|c|c|c|c|c|c|c|}
\hline \multicolumn{7}{|c|}{ Sección 3. Historia de Costa Rica Precolombina } \\
\hline \multicolumn{7}{|c|}{ COSTA RICA PRECOLOMBINA } \\
\hline Área Cultural & Grupo cultural & Tipo de producción & Materiales & Técnica & Elementos diseño & Tipología \\
\hline & \multirow{4}{*}{ Nicoya } & & & Relieves & Monstruo & Vasijas trípodes \\
\hline & & & & & & Máscaras \\
\hline & & & & & Dioses & \\
\hline & & & & & Murciélago & Colgante \\
\hline & \multirow[b]{4}{*}{ Vertiente Atlántica } & Escultura & Jade & Talla & Humanos & Estatuas \\
\hline & & & Piedra & & Animales & Altares \\
\hline & & & Arcilla & & Guerreros & Figuras humanas \\
\hline & & & Calcedonia & & Reptiles & \\
\hline & \multirow{11}{*}{ Diquís } & & & & & Estatuas \\
\hline & & Orfebrería & Tumbaga & Laminado & Aves bicéfalas & Colgantes \\
\hline & & & Oro & Repujado & Jaguar & Máscaras \\
\hline & & & & & Músicos & Figuras \\
\hline & & & & & Bailarines & Discos o platos \\
\hline & & & & & Mono & \\
\hline & & & & & Águila & \\
\hline & & & & & Zopilote & \\
\hline & & Cerámica & & Línea negra & & Figura femenina \\
\hline & & & & Línea roja & & \\
\hline & & & & Monocroma & & \\
\hline
\end{tabular}

Fuente: Elaboración propia. 
Esta investigación presenta similitudes con la tesis de Huertas (1953). Las descripciones y caracterizaciones de los objetos parten de apreciaciones personales, en las que supone relaciones y significados sin el uso de un sustento teórico. Enfatiza en los materiales, tipos de objetos y técnicas de fabricación. También se reconocen algunas diferencias entre ambos trabajos. En primera instancia, el uso de los modelos de historia antigua. En este caso, el autor establece una separación de las áreas culturales precolombinas de Costa Rica a partir de la identificación de zonas geográficas: Nicoya, Vertiente del Atlántico y Diquís y omite el uso de los grupos culturales allí asentados que si utilizó Huertas (Chorotegas, Huetares y Bruncas). Este cambio denota la influencia de los estudios arqueológicos que se desarrollaban, cuyos resultados ya se publicaban y difundían.

Por otra parte, el término orfebrería es utilizado por el autor para nombrar los objetos elaborados en cualquier tipo de metal. Antes, Huertas se refirió a esta producción como trabajos en metal o trabajos metálicos. La inclusión del término orfebrería es una mención que utiliza por primera vez Carlos Aguilar, cuatro años antes de la investigación de Revollar. En resumen, su análisis enfatiza en las áreas de influencia cultural. Da continuidad al trabajo de Huertas, al acentuar los aspectos visibles de los objetos, propios de las descripciones de la arqueología y adiciona algunos elementos simbólicos.

Hasta el año 1960, el arte costarricense se desarrollaba al margen de las vanguardias que surgieron después de la Segunda Guerra Mundial (1945). Mantenía una esencia local y costumbrista, aunque ya los artistas intentaban introducir temas de corte social, como reacción a la tradición (Rojas, 2003, p. 93). Esta década ve partir a muchos estudiantes hacia el extranjero, lo cual incide en la introducción del arte abstracto en el país y la conformación del Grupo Ocho, que dominó la escena del arte durante este periodo y parte de la década siguiente. La EAP experimentó una dinámica de tensión entre los principios de la enseñanza academicista y el arte de las vanguardias, lo que motivó el interés en estudiantes y docentes por conocer lo que sucedía en la escena internacional.

El señor Luis Paulino Delgado recuerda que, en el año 1964, como producto de un convenio internacional, se realizó un intercambio académico con la Universidad de Kansas. Gracias a este, llegó un profesor norteamericano referido como Mr. Tef, quien impartió el primer curso libre de orfebrería en la EAP, para el cual, se improvisó un taller con equipo muy básico y pocas herramientas. En el archivo histórico de la Biblioteca Francisco Amighetti no se encontraron documentos de este periodo, ya que la información más antigua referente a la orfebrería corresponde al año 1972. Sin embargo, existe un vínculo claro entre los intereses de aquellas generaciones de alumnos, profesores y la apertura de cursos impartidos por docentes extranjeros. 
La década de 1960 se convirtió en un periodo que propició el estudio y la preservación de la orfebrería precolombina con el Decreto sobre Control de la Explotación y Comercio de Reliquias Históricas; la fundación del Museo Arqueológico y Numismático del BCCR; la publicación de los estudios arqueológicos de Lothrop y Stone; la catalogación de Aguilar para la colección de objetos de oro; la formación de estudiantes en el extranjero; el auge de la etnohistoria y el convenio con la Universidad de Kansas. Además, con el interés por el aprendizaje de la técnica en la EAP se trazó la ruta hacia la orfebrería y se fortalecieron las bases para futuros acontecimientos como la profesionalización de la Arqueología y la valoración de estos objetos en otras dimensiones. Esto sucederá en la década posterior.

\section{La década de 1970: el corto auge de la orfebrería y la nueva mirada}

Como ya se mencionó, en el año 1972 se publica el libro la Colección de Objetos Indígenas de Oro del BCCR, que incluye el estudio de catalogación desarrollado en 1964 por el arqueólogo Carlos Aguilar Piedra. Pero, esta vez, con apoyo de la UCR. El documento era el estudio más completo sobre orfebrería precolombina realizado en el país y, aunque no se trata de una tesis, resulta pertinente su reseña, ya que se convirtió en referente para las investigaciones posteriores. Se trata de una catalogación arqueológica y museográfica. El autor delimita la procedencia de los objetos y selecciona grupos de ellos, a partir de aspectos funcionales y tecnológicos. Elabora un grupo basado en la técnica de la fundición, debido a la cantidad y variedad de objetos fabricados con este proceso. Aquí, destacan, además, categorías referidas a los motivos: aspecto artístico, la espiral, el lagarto y la serpiente. También, elabora una selección basada en figuras de realismo y figuras de fantasía para establecer un apartado sobre los elementos constitutivos de esas figuras. Seguidamente, realiza un estudio tipológico realmente extenso, en el que divide los grupos con base en la representación.

El autor aborda la producción con los términos: objetos indígenas en oro, objetos de metal y orfebrería; a los artesanos indígenas les denomina orfebres. La inclusión del término orfebre, identifica un rango de especialización, con dominio material y tecnológico, el cual se traduce en una valoración a la calidad de la producción que analiza. Aguilar (1972) incluye, además, el término "joya" (p. 4) para referirse a las piezas de orfebrería utilizadas como ornamentos para el cuerpo (Imagen 1). Su estudio evidencia un marcado aspecto teórico metodológico influenciado por información extraída de documentos sobre excavaciones arqueológicas profesionales. De acuerdo con Solórzano (2011) estas "pueden sugerir las vías de interpretación para la producción precolombina en su estética y estilo" (p. 3). Aguilar introduce el aspecto artístico como categoría de análisis, una innovación que abre el camino a la valoración alternativa de estas obras y coincide, además, con el interés de las nuevas vanguardias del arte europeo por el arraigo étnico (respuesta al clasicismo). El concepto de lo artístico será incorporado en estudios posteriores sobre arte precolombino. 
Imagen 1. Colgante con forma de ave Pacífico Sur / 700-1550 d.C.

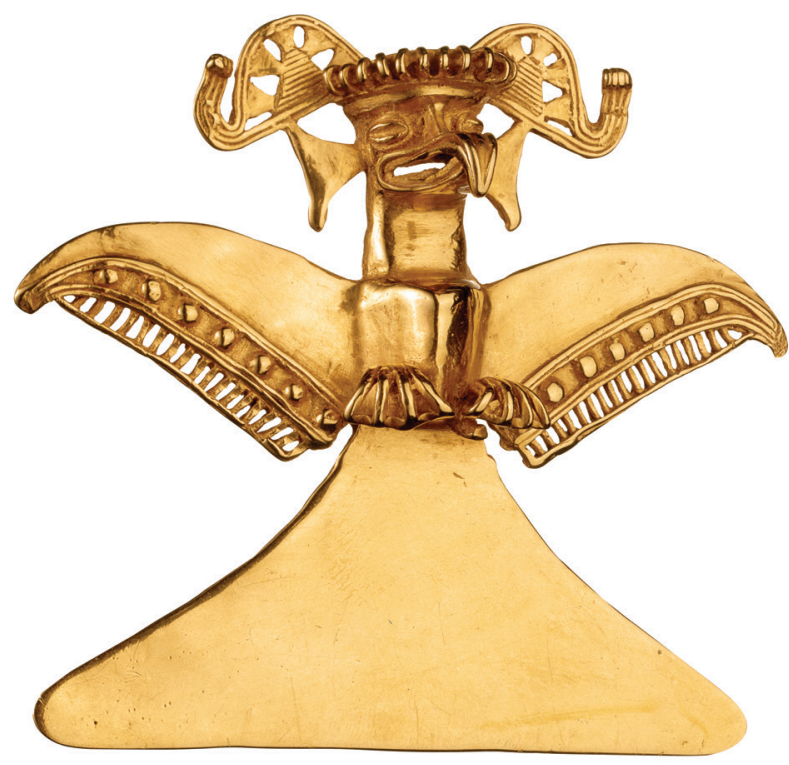

Fuente: Colección Museos del Banco Central.

\section{Vilma Madriz (1974)}

Arte Precolombino en Mesoamérica es el título de la tesis de Licenciatura en Artes Plásticas que desarrolló Vilma Madriz en 1974. La autora analiza la producción de arte precolombino en la región mesoamericana y suramericana. De la primera, selecciona los grupos Mayas, Aztecas, Copán, Coclé y los costarricenses. En la segunda incluye a Perú y Colombia, con poblaciones específicas en cada caso. La investigación profundiza en aspectos geográficos, históricos, sociales y simbólicos. Además de los formales y materiales, que han sido considerados desde el inicio de la exploración en este campo.

Se refiere a la producción como orfebrería o metalurgia, indistintamente. También, integra el término joya al citar las

piezas de ornamentación para el cuerpo. Madriz (1974) denomina "orfebre" (p. 11) al artesano indígena especializado en el dominio técnico de los metales, lo cual, no se había encontrado hasta ahora en las tesis. Es decir, Madriz establece una continuidad en el uso de estas denominaciones, tanto para las piezas como para los indígenas que las fabricaron, lo que implica un reconocimiento al trabajo del artesano. Además, refleja la influencia de la catalogación que había realizado de Carlos Aguilar dos años atrás.

La autora desarrolla mayor especificidad para establecer los grupos de objetos al delimitarlos y ampliarlos. En primer lugar, a partir de los materiales: oro, plata y cobre. En segundo lugar, enfocado en la técnica: martillado, cera perdida, fundición, chapeado, dorado, repujado, filigrana, soldadura, laminado, bajo y alto relieve e incrustación de piedras preciosas. En tercera instancia, destaca los tipos: pendientes, orejeras, anillos, broches. Detalla los procesos técnicos de fabricación con más precisión. Es posible, además, reconocer la inclusión de aspectos sobre la visión cultural, social y el papel o función de los objetos de orfebrería en las sociedades precolombinas que estudia. Menciona costumbres y rituales en las descripciones y establece el estilo como una categoría para el análisis de las culturas precolombinas, una particularidad de su investigación. En el análisis de la región de Mesoamérica destaca la metalurgia como una de las formas de producción de artefactos (Cuadro 3). 


\section{Tabla 3. Arte Precolombino en Mesoamérica, Vilma Madriz (1974)}

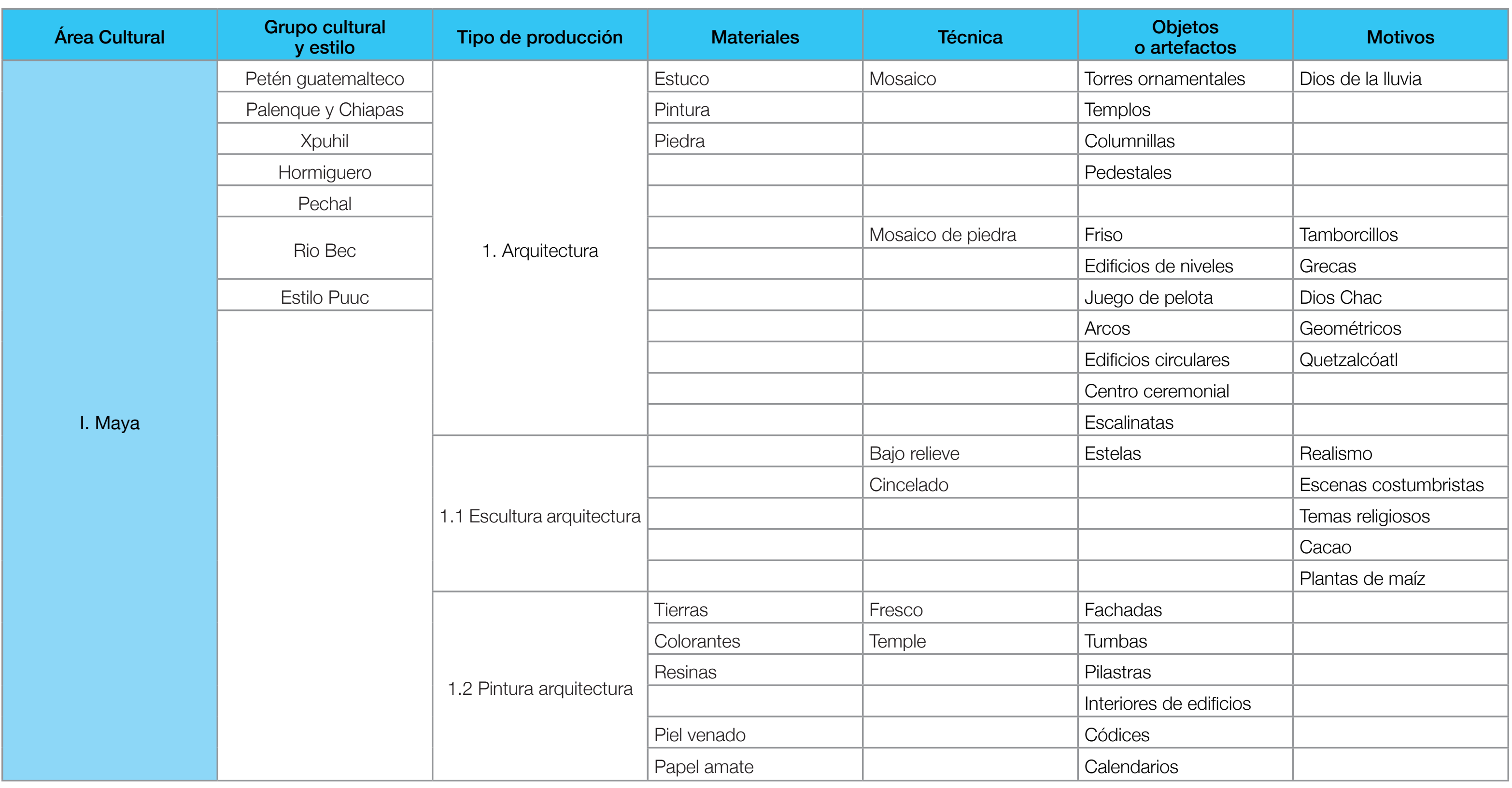




\begin{tabular}{|c|c|c|c|c|c|c|}
\hline Área Cultural & $\begin{array}{l}\text { Grupo cultural } \\
\text { y estilo }\end{array}$ & Tipo de producción & Materiales & Técnica & $\begin{array}{c}\text { Objetos } \\
\text { o artefactos }\end{array}$ & Motivos \\
\hline \multirow{28}{*}{ I.Maya } & & \multirow{9}{*}{ 2. Cerámica } & Arcilla & Policroma & Platos trípodes & Vida cotidiana \\
\hline & & & & Pintura chorreada & Platos tetrápodos & Escenas rituales \\
\hline & & & & & Vasijas esfinge & Zoomorfos \\
\hline & & & & & Vasos altos & Códices \\
\hline & & & & & Incensarios & Animales y dioses \\
\hline & & & & & Sellos & Jugadores de pelota \\
\hline & & & & & Tambores musicales & Guerreros \\
\hline & & & & & Máscaras & \\
\hline & & & & & Figurillas & \\
\hline & & \multirow{7}{*}{ 3. Arte lapidario } & Jade & Percusión & Orejeras & \\
\hline & & & Jadeíta & Corte & Collares & \\
\hline & & & Serpentina & Desgaste & Broches & \\
\hline & & & Cuarzo & Perforación & Pendientes & \\
\hline & & & Concha & Pulido & Anillos & \\
\hline & & & Caracol marino & & Figuras y máscaras & \\
\hline & & & Hueso & & Mosaico & \\
\hline & & \multirow{7}{*}{ 4. Metalurgia } & Oro & Martillado & & \\
\hline & & & Plata & Cera perdida & & \\
\hline & & & Cobre & Chapado & & \\
\hline & & & & Dorado & & \\
\hline & & & & Filigrana & & \\
\hline & & & & Repujado & & \\
\hline & & & & Soldadura & & \\
\hline & & \multirow{5}{*}{ 5. Madera } & & & Dinteles & \\
\hline & & & & & Bancos & \\
\hline & & & & & Canoas & \\
\hline & & & & & Máscaras & \\
\hline & & & & & Arcos & \\
\hline
\end{tabular}




\begin{tabular}{|c|c|c|c|c|c|c|}
\hline Área Cultural & $\begin{array}{l}\text { Grupo cultural } \\
\text { y estilo }\end{array}$ & Tipo de producción & Materiales & Técnica & $\begin{array}{l}\text { Objetos } \\
\text { o artefactos }\end{array}$ & Motivos \\
\hline \multirow{7}{*}{ I. Maya } & & \multirow{7}{*}{ 6. Cestería y tejido } & Algodón & Brocado & Esteras & \\
\hline & & & Pelo de conejo & Bordado & Petates & \\
\hline & & & Caracoles & Sarga & Sombreros & \\
\hline & & & Plumas & Gasa & Abanicos & \\
\hline & & & & Telas de cintura & Lienzos & \\
\hline & & & & & Tapicería & \\
\hline & & & & & Indumentaria & \\
\hline \multirow{20}{*}{ II. Azteca } & & \multirow{4}{*}{ 1. Arquitectura } & & & Acueductos & Dios Tláloc \\
\hline & & & & & Santuarios & Huitzilopochtli \\
\hline & & & & & Juego de pelota & Quetzalcóatl \\
\hline & & & & & Palacios & \\
\hline & & \multirow{7}{*}{ 2. Escultura } & Obsidiana & & Monumentos & Motivos religiosos \\
\hline & & & Piedra volcánica & & Vasos ceremoniales & Motivos realistas \\
\hline & & & Cráneos humanos & & Altares & Hombres y animales \\
\hline & & & Turquesa & & Piedra del Sol & Plantas \\
\hline & & & Concha & & Cuchillos & Dioses \\
\hline & & & Madera & & & Serpientes enroscadas \\
\hline & & & & & & Vida cotidiana \\
\hline & & \multirow{6}{*}{ 3. Madera } & & Talla & Tronos & Motivos geométricos \\
\hline & & & & & Cunas & Jeroglíficos \\
\hline & & & & & Tarimas & Rostros humanos \\
\hline & & & & & Canoas y remos & Animales \\
\hline & & & & & Escultura & \\
\hline & & & & & Tambores & \\
\hline & & \multirow{3}{*}{ 4. Cerámica } & & Bicroma & Incensarios bicónicos & Dioses de agricultura \\
\hline & & & & Policroma & Vasos de alta base & Códices \\
\hline & & & & & Platos fondo plano & \\
\hline
\end{tabular}




\begin{tabular}{|c|c|c|c|c|c|c|}
\hline Área Cultural & $\begin{array}{l}\text { Grupo cultural } \\
\text { y estilo }\end{array}$ & Tipo de producción & Materiales & Técnica & $\begin{array}{c}\text { Objetos } \\
\text { o artefactos }\end{array}$ & Motivos \\
\hline \multirow{11}{*}{ II. Azteca } & & \multirow{5}{*}{$\begin{array}{l}\text { 5. Orfebres } \\
\text { metalurgistas }\end{array}$} & Oro & Martillado & Joyas & \\
\hline & & & Plata & Dorado & Pendientes & \\
\hline & & & Cobre & Fundido & Orejeras & \\
\hline & & & & Laminado & Anillos & \\
\hline & & & & Filigrana & Broches & \\
\hline & & \multirow{5}{*}{ 6. Plumaria } & & & Escudos & \\
\hline & & & & & Abanicos & \\
\hline & & & & & Penachos & \\
\hline & & & & & Insignias & \\
\hline & & & & & Prendas de vestir & \\
\hline & & 7. Escritura & Papel de maguey & & Códice Borbónico & Jeroglífico \\
\hline \multirow{8}{*}{ III. Copán } & \multirow{8}{*}{ Cocle } & \multirow{8}{*}{ 8. Orfebres } & & Cera perdida & & \\
\hline & & & & Laminado & & \\
\hline & & & & Baño de oro & & \\
\hline & & & & Martillado & & \\
\hline & & & & Relieve & & \\
\hline & & & & Soldadura & & \\
\hline & & & & Ensamble & & \\
\hline & & & & Incrustaciones & & \\
\hline
\end{tabular}




\begin{tabular}{|c|c|c|c|c|c|c|}
\hline Área Cultural & $\begin{array}{c}\text { Grupo cultural } \\
\text { y estilo }\end{array}$ & Tipo de producción & Materiales & Técnica & $\begin{array}{c}\text { Objetos } \\
\text { o artefactos }\end{array}$ & Motivos \\
\hline \multirow{16}{*}{ IV. Costa Rica } & \multirow{3}{*}{$\begin{array}{l}\text { Chorotegas } \\
\text { Guanacaste }\end{array}$} & \multirow{3}{*}{ 1. Cerámica } & Arcilla & & Vasijas con jaguar & Serpiente \\
\hline & & & Jadeíta & & Colgante & Cocodrilo \\
\hline & & & & & & Fertilidad \\
\hline & \multirow{12}{*}{ Bruncas } & \multirow{5}{*}{ 1. Orfebrería } & Oro & Laminado & Máscaras & Símbolos totémicos \\
\hline & & & Oro-cobre & Repujado & Discos & Animales \\
\hline & & & Pirita & Falsa filigrana & Platos & Águilas \\
\hline & & & & Engaste & & \\
\hline & & & & Martillado & & \\
\hline & & \multirow{7}{*}{ 2. Cerámica } & & Bicroma & Ocarinas & Línea negra y roja \\
\hline & & & & Monocroma & Flautas & Figuras femeninas \\
\hline & & & & & & Fertilidad y maternidad \\
\hline & & & & & & Motivos bicéfalos \\
\hline & & & & & & Fauna local \\
\hline & & & & & & Vida marina \\
\hline & & & & & & Jaguar \\
\hline & Huetares Caribe & & & & & \\
\hline
\end{tabular}

Fuente: Elaboración propia. 
Sobre la producción realizada en Costa Rica, la autora refiere al modelo de división por grupos culturales e incorpora el modelo por áreas de influencia. De esta manera, incluye los modelos utilizados por Huertas (1953) y Revollar (1968). Sin embargo, las áreas de influencia, en este caso, son presentadas como estilos de los objetos. Es decir, Chorotega / estilo Guanacaste; Brunca / estilo Diquís y Huetares / estilo Vertiente del Atlántico. La síntesis que realiza es un modelo mixto que relaciona grupo cultural y zona de influencia. Además, destaca otras cualidades en los objetos más allá de sus rasgos materiales y técnicos, al distinguir los motivos y la decoración. En términos generales, la investigación de Madriz integra las categorías de lo cultural y lo social y la función de los artefactos en las sociedades precolombinas que estudia. Incluye costumbres y rituales como parte de las descripciones y establece el estilo como una categoría para el análisis de las culturas precolombinas, un aporte de su investigación.

De acuerdo con Solórzano (2011), el quehacer arqueológico nacional es institucionalizado en el año 1975, con la apertura de la carrera de Arqueología en la UCR. Ese mismo año, Luis Ferrero (1930-2005) publica su libro Costa Rica Precolombina, texto referente para el estudio de la temática. Ferrero elabora una síntesis de las investigaciones arqueológicas realizadas hasta el año 1974, con el objetivo de difundir el pasado artístico nacional. La selección de los objetos que incluye como casos de estudio se fundamenta en la existencia de un realismo mítico, en el detalle plástico presente en los objetos y en el goce estético de las obras, sin restar importancia a la caracterización tipológica o a la interpretación simbólica de las mismas.

Para este momento, el método de análisis del arte es el iconográfico-iconológico, a través de este son analizadas las obras en las investigaciones artísticas y arqueológicas. La primera línea analiza los rasgos visibles en la obra. La segunda línea de este método consiste en su interpretación desde el contexto cultural que la produce, lo cual abre paso a una nueva lectura de la producción precolombina y se incluyen los aspectos inherentes a la realidad de cada población, sus costumbres, creencias, estilo de vida, cosmovisión y rasgos particulares. Estos elementos contextuales incidieron en las investigaciones posteriores. En esta década, algunos artistas plásticos utilizaron los motivos del arte precolombino en su obra, lo que denota la influencia y difusión del conocimiento y el interés por esta producción (Rojas, 2003, p.108).

En el año 1972, según detalla Luis Paulino Delgado, los planes académicos de la EAP se encontraban en franca renovación. Se diseñó la cátedra de orfebrería como un especialidad de licenciatura y, por medio de becas al exterior, varios docentes se especializaron en el campo. Ese año, Delgado realizó su Maestría con énfasis en grabado y orfebrería, con lo que comenzó a impartir un curso introductorio. En los años posteriores, recomendó a los docentes Mario 
Imagen 2. BCCR 0001. Colgante en forma de águila arpía. Pacífico Sur / 700-1500 d.C.

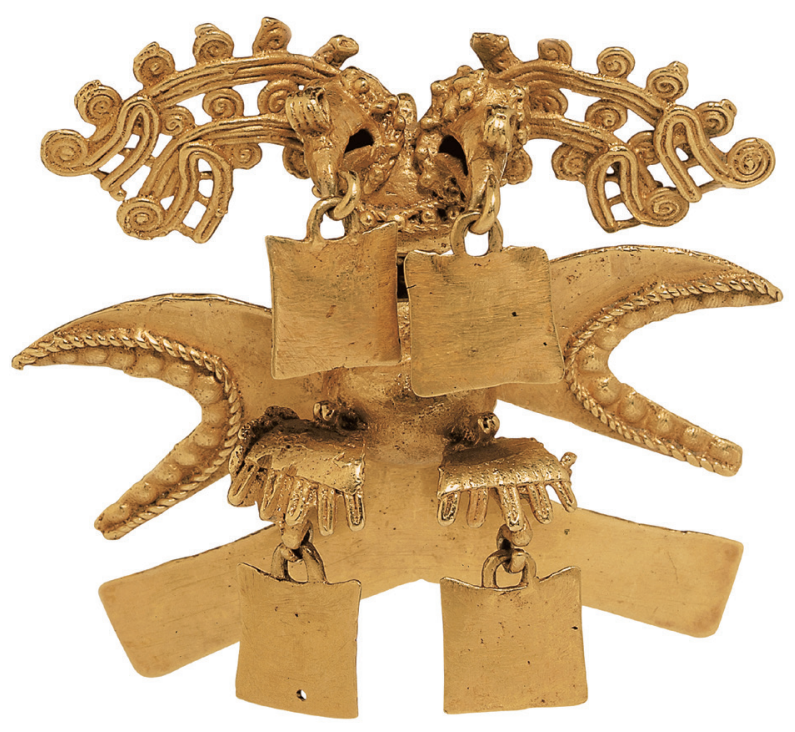

Fuente: Colección Museos del Banco Central de Costa Rica (Fotografía Mike \& Corinna Blum).
Parra y Elizabeth Thompson para hacer sus maestrías en la especialidad, según recuerda Herberth Zamora. También, se contó con la experiencia del docente austríaco-norteamericano Herberth Bickner, especialista en la técnica de esmaltado.

En los registros históricos de la biblioteca Francisco Amighetti se localizó el plan de estudios de la Licenciatura en Orfebrería, al que se hizo referencia. Consistía en cuatro cursos semestrales, tres de los cuales se enfocaban en el aprendizaje de técnicas y materiales. El último, se reservaba para el desarrollo de un proyecto comprensivo a elección del estudiante. Sin embargo, la Licenciatura en Orfebrería no se puso en práctica, a pesar del interés mostrado por los estudiantes y de que la escuela contaba con un taller equipado, el cual, según Delgado, requirió de una inversión de varios millones (Imagen 2).

\section{Claudia Corrales (1975)}

En el año 1975, Claudia Corrales presenta su tesis de Licenciatura en Bellas Artes titulada Representaciones y estilos decorativos de la metalurgia costarricense. Es la única tesis encontrada que aborda el estudio de la orfebrería de manera exclusiva. Se trata de una investigación que toma como base el Catálogo de objetos indígenas de oro del BCCR, realizado por Carlos Aguilar en 1972. El estudio de Corrales retoma el modelo histórico de las tres áreas de población indígena, tal y como lo realizó Huertas en 1953, un modelo que parecía superado, teniendo en cuenta los enfoques de tesis anteriores y los estudios arqueológicos recientes. El modelo de división por grupos de población (Chorotegas, Bruncas y Huetares) caló profundamente, se difundió a nivel educativo (Coladán \& Corrales, 2000, p.74) y se mantuvo incluso hasta la década de los años 1990, debido a su simplicidad.

La autora enfatiza en otros aspectos de los objetos, más allá de lo arqueológico. Considera que la orfebrería es decorativa y coincide con las apreciaciones de Luis Ferrero en su libro Costa Rica Precolombina, en el cual, la describe como una producción de objetos 
pequeños, preciosistas, refinados y colmados de símbolos. En este libro, Ferrero utiliza el modelo por áreas de influencia, que tuvo difusión en el sistema educativo a partir del año 1977 (Corrales, 2000, p. 33).

En la tesis se describen instrumentos y materiales con profundización en las técnicas y sus procesos de manufactura: martillado, fundición, coloración y unión, las cuales alterna con información histórica. También, destaca el aspecto decorativo de las piezas, estudia los motivos animales encontrados, entre ellos: serpiente, lagarto, águila, rana y jaguar. La descripción de los motivos es realizada a partir del simbolismo conferido a estos, desde distintos contextos geográficos y culturales. Elabora algunos supuestos sobre el significado de estas figuras en el arte precolombino: "todo arte es fiel manifestación de las necesidades psíquicas, sociales y religiosas de su época" (Corrales, 1975, p. 35).

Es notorio su interés por establecer relaciones entre la representación y elementos espirituales, emocionales o religiosos, aspectos no desarrollados en las tesis anteriores. Describe con detalle las características de la decoración encontrada en la orfebrería y enlista al menos diez denominaciones de formas compuestas de fantasía (hombre y animal) y siete elementos decorativos encontrados en las piezas de orfebrería: líneas, cordones, listón liso, listón dentado, triángulos solos o en series, motivo lagarto, motivo serpiente, entre otros. (Cuadro 4). 
Tabla 4. Representaciones y estilos decorativos de la metalurgia precolombina costarricense, Claudia Corrales (1975)

\begin{tabular}{|c|c|c|c|c|}
\hline Áreas culturales & Técnica & $\begin{array}{c}\text { Fauna en el } \\
\text { motivo } \\
\text { decorativo }\end{array}$ & \multicolumn{2}{|r|}{ Aspecto decorativo } \\
\hline \multirow{14}{*}{$\begin{array}{c}\text { Chorotega - Guanacaste } \\
\text { Huetar - Norte y Atlántico } \\
\text { Bruncas - Pacífico Sur }\end{array}$} & 1. Martillado & 1. Serpiente & \multirow{11}{*}{$\begin{array}{l}\text { 1. Figura humana y de fantasía } \\
\text { 1.1 Hombre - Ave } \\
\text { 1.2 Hombre - Jaguar } \\
\text { 1.3 Hombre - Lagarto } \\
\text { 1.4 Hombre - Ave - Jaguar } \\
\text { 1.5 Hombre - Ave - Rana } \\
\text { 1.6 Hombre - Ave- Rana - Lagarto } \\
\text { 1.7 Lagarto - Hombre } \\
\text { 1.8 Lagarto - Jaguar } \\
\text { 1.9 Rana - Lagarto } \\
\text { 1.10 Rana - Jaguar }\end{array}$} & \\
\hline & 1.1 Recochado & 2. Lagarto & & \\
\hline & 1.2 Repujado & 3. Águilas & & \\
\hline & 2. Dorado & 4. Ranas & & \\
\hline & 2.1 Mise en coleur & 5. Jaguar & & \\
\hline & 2.3 Baño de oro & & & \\
\hline & 3. Uniones & & & \\
\hline & 3.1 Presión & & & \\
\hline & 3.2 Soldadura & & & \\
\hline & 3.3 Remaches & & & \\
\hline & 3.4 Mecánicas & & & \\
\hline & & & $\begin{array}{l}\text { 2. Elementos decorativos } \\
\text { 2.1 Líneas } \\
2.2 \text { Cordones } \\
\text { 2.3 Listón liso } \\
\text { 2.4 Dentado } \\
\text { 2.5 Botones }\end{array}$ & $\begin{array}{l}\text { Rectas } \\
\text { Quebradas } \\
\text { Zigzag } \\
\text { Espiral } \\
\text { Liso } \\
\text { Seccionado en rombos } \\
\text { Torzal } \\
\text { Trenzado } \\
\text { Yuxtaposición }\end{array}$ \\
\hline & & & $\begin{array}{l}\text { 3. Motivos } \\
\text { 3.1 Lagarto }\end{array}$ & $\begin{array}{l}\text { Espiral con cordón recto } \\
\text { Forma de U con espiral } \\
\text { Cordón doble con asa cerrada } \\
\text { Espiral doblada hacia afuera y desunido } \\
\text { En U con espiral sobrepuesta } \\
\text { Cordón doble y espirales dobles } \\
\text { Lateral con forma de S }\end{array}$ \\
\hline & & & 3.2 Serpiente & $\begin{array}{l}\text { Cabeza en triángulo y rombo } \\
\text { En espiral } \\
\text { Cordón liso } \\
\text { Cordón yuxtapuesto } \\
\text { Dos cabezas opuestas }\end{array}$ \\
\hline
\end{tabular}




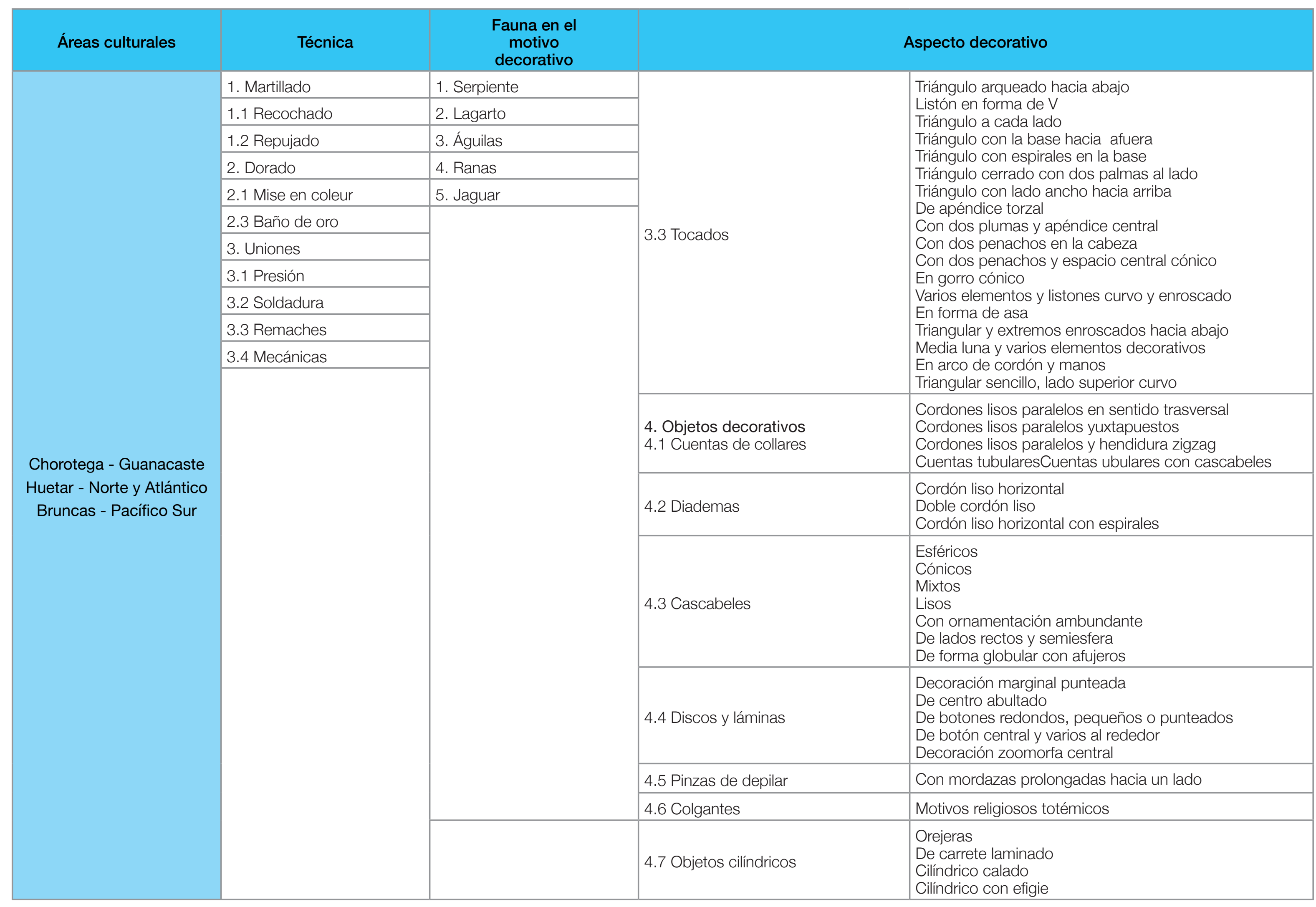




\begin{tabular}{|c|c|c|c|c|}
\hline Áreas culturales & Técnica & $\begin{array}{c}\text { Fauna en el } \\
\text { motivo } \\
\text { decorativo }\end{array}$ & & Aspecto decorativo \\
\hline \multirow{20}{*}{$\begin{array}{l}\text { Chorotega - Guanacaste } \\
\text { Huetar - Norte y Atlántico } \\
\text { Bruncas - Pacífico Sur }\end{array}$} & 1. Martillado & 1. Serpiente & \multirow{3}{*}{$\begin{array}{l}\text { 5. Tipo de aves } \\
\text { 5.1 Veragua }\end{array}$} & \multirow{3}{*}{$\begin{array}{l}\text { Veragua sencillo } \\
\text { Veragua decorado } \\
\text { Veragua de collar }\end{array}$} \\
\hline & 1.1 Recochado & 2. Lagarto & & \\
\hline & 1.2 Repujado & 3. Águilas & & \\
\hline & 2. Dorado & 4. Ranas & 5.2 Jalapa & \\
\hline & 2.1 Mise en coleur & 5. Jaguar & 5.3 La Vaca & \\
\hline & 2.3 Baño de oro & & 5.4 Sierpe & \\
\hline & 3. Uniones & & 5.5 Chánguina & \\
\hline & 3.1 Presión & & 5.6 Guanacaste & \\
\hline & 3.2 Soldadura & & \multirow{3}{*}{5.7 Osa } & \multirow{3}{*}{$\begin{array}{l}\text { De dos cabezas } \\
\text { Motivo lagarto } \\
\text { Cola en listón y alas arqueadas }\end{array}$} \\
\hline & 3.3 Remaches & & & \\
\hline & \multirow[t]{10}{*}{ 3.4 Mecánicas } & & & \\
\hline & & & 5.8 Guápiles & \\
\hline & & & 5.9 Palmar & \\
\hline & & & 5.10 Burica & \\
\hline & & & 5.11 Línea Vieja & \\
\hline & & & 5.12 Pococí & \\
\hline & & & 5.13 Brus & \\
\hline & & & 5.14 Barú & $\begin{array}{l}\text { De elementos arqueados en el extremo } \\
\text { De cabeza de lagarto en doble cordón }\end{array}$ \\
\hline & & & 5.15 Diquís & \\
\hline & & & 5.16 Carbonera & \\
\hline
\end{tabular}




\begin{tabular}{|c|c|c|c|c|}
\hline Áreas culturales & Técnica & $\begin{array}{c}\text { Fauna en el } \\
\text { motivo } \\
\text { decorativo }\end{array}$ & & Aspecto decorativo \\
\hline \multirow{15}{*}{$\begin{array}{l}\text { Chorotega - Guanacaste } \\
\text { Huetar - Norte y Atlántico } \\
\text { Bruncas - Pacífico Sur }\end{array}$} & 1. Martillado & 1. Serpiente & \multirow{12}{*}{ 6. Figuras humanas } & \multirow{12}{*}{$\begin{array}{l}\text { Sencilla } \\
\text { Pierna en } \cup \\
\text { Tocado de plumas } \\
\text { Tocado de cordón } \\
\text { Tocado en torzal } \\
\text { Cuerpo fusiforme } \\
\text { Grupo maraqueros } \\
\text { Grupo mùsicos } \\
\text { Figuras bicéfalas } \\
\text { Figura humana entre dos soportes } \\
\text { Figura de tocado en arco } \\
\text { Figura de tocado de serpiente } \\
\text { Figura de hombre felino } \\
\text { Figura de hombre lagarto } \\
\text { Figura de hombre ave } \\
\text { Figura con ganchos para placas }\end{array}$} \\
\hline & 1.1 Recochado & 2. Lagarto & & \\
\hline & 1.2 Repujado & 3. Águilas & & \\
\hline & 2. Dorado & 4. Ranas & & \\
\hline & 2.1 Mise en coleur & 5. Jaguar & & \\
\hline & 2.3 Baño de oro & & & \\
\hline & 3. Uniones & & & \\
\hline & 3.1 Presión & & & \\
\hline & 3.2 Soldadura & & & \\
\hline & 3.3 Remaches & & & \\
\hline & \multirow[t]{5}{*}{ 3.4 Mecánicas } & & & \\
\hline & & & & \\
\hline & & & $\begin{array}{l}\text { 7. Figuras de animales } \\
\text { 7.1 Ranas }\end{array}$ & $\begin{array}{l}\text { De tipo sencillo } \\
\text { De decoración dorsal } \\
\text { De tipo Vaca } \\
\text { Con lengua bífida } \\
\text { Con decoración bucal de espirales } \\
\text { Ranas sobre listón } \\
\end{array}$ \\
\hline & & & 7.2 Otros animales Mono & $\begin{array}{l}\text { Mono } \\
\text { Araña } \\
\text { Peces } \\
\text { Tortuga } \\
\text { Langosta marina } \\
\text { Cangrejo } \\
\end{array}$ \\
\hline & & & 7.3 Otras figuras & $\begin{array}{l}\text { De cola curvada hacia adelante } \\
\text { Figura de ala y media luna } \\
\text { Figuras de ala y cola }\end{array}$ \\
\hline
\end{tabular}

Fuente: Elaboración propia. 
La autora, desarrolla apreciaciones estéticas y de diseño, como la línea, la curva, la estilización de la forma, entre otros, así, la función de los objetos de orfebrería es meramente decorativa. Aguilar (1972) detallaba en su libro que, la orfebrería es considerada como: "adornos para ser llevados en el cuerpo, objetos de lujo bienes o riqueza dignos de ostentación en la vida y el más allá" (p. 5). La función que establece Aguilar es más amplia, ya que abarca lo social, al definir los objetos como de lujo y, además, incluye una función religiosa al afirmar que son dignos de ostentación en la vida y después de ella.

Corrales enfoca su investigación en la categoría que, anteriormente, Aguilar propuso como lo artístico. Así, esta tesis se convierte no solo en la primera referencia exclusiva sobre el tema de orfebrería, sino que la analiza desde el arte, aspectos estéticos y decorativos, con especial interés en los motivos de la naturaleza y la fauna, sin restar importancia a los elementos formales y materiales que se enfatizaron en investigaciones anteriores. Las características y grupos que establece la autora son variadas y detalladas, producto del saber arqueológico que se integra con mayor formalidad a las investigaciones sobre el tema. Así lo destaca Corrales (1975): "la intención principal es hacer un estudio del aspecto decorativo de los objetos de metal indígenas costarricenses, dando énfasis a la orfebrería y tumbaga y a sus diferentes representaciones" (p. v).

Los términos metalurgia, metalistería, joya y orfebrería son utilizados, indistintamente, para referirse a la producción. También, incluye la denominación "joyería prehispánica" (p. 32). Corrales plantea, entonces, una propuesta que posiciona nuevas características en los objetos, a través de la categoría de lo artístico y lo decorativo, que abarca desde aspectos orientados al diseño, hasta la representación y su significado. Además, establece que la función de la orfebrería está en la ornamentación del cuerpo.

Durante la década de 1970, los artistas plásticos incursionaban en un arte figurativo con estilo propio, adoptaron el expresionismo, el conceptualismo, la abstracción geométrica y el realismo mágico. El paisaje toma fuerza, pero, sobre todo, el retorno hacia lo propio, ya que los estilos de las vanguardias internacionales de posguerra no se sintieron cercanos y pronto desaparecieron por completo de la escena (Rojas, 2003, p. 107). El arraigo por los temas locales fue un elemento recurrente en la producción artística costarricense. De manera que, el interés por el tema precolombino, significaba también un retorno a las raíces (Imagen 3).

El profesor Herberth Zamora recuerda que, a su ingreso en la EAP en el año 1975, ya Luis Paulino Delgado impartía varios cursos de orfebrería y Herberth Bickner impartía esmaltado. Recordemos que es el mismo año en el que se abrió la carrera de Arqueología en la UCR, lo cual, según Zamora, no tuvo relación o incidencia en el interés por la orfebrería en la EAP. Delgado, por su parte, supone una conciencia más clara por parte de docentes y 
Imagen 3. BCCR- 1247. Colgante en forma de humana con máscara de águila arpía. Pacífico Sur / 700-1500 d.C

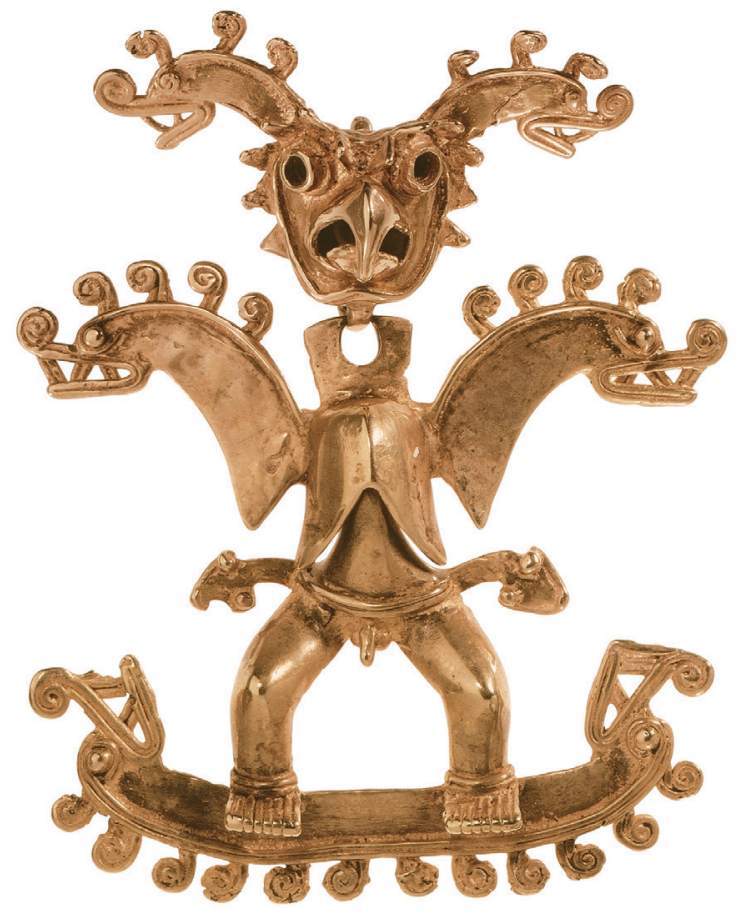

Fuente: Colección Museos del Banco Central de Costa Rica (Fotografía Mike \& Corinna Blum).

Ios esquimales y el arte negro. Agrupa la producción precombina según é énfasis que ella misma determina para cada cultura y desarrolla, brevemente, la producción orfebre. En cuanto a la tipología para estos objetos destacan collares, brazaletes, sortijas incrustadas, entre otros. Con respecto a la técnica, refiere a: fundición, soldadura, filigrana, lapidaria, batido, realzado y grabado (Cuadro 5). 
Tabla 5. Arte indígena americano. Susana Tello (1977)

\begin{tabular}{|c|c|c|c|c|c|}
\hline \multicolumn{6}{|c|}{ I. MAYAS } \\
\hline Área cultural & Tipo de producción & Material & Técnica & Objetos o artefactos & Motivos artísticos \\
\hline \multirow{5}{*}{ 1.1 Mayas clásicos } & 1. Arquitectura & $\begin{array}{l}\text { Piedra } \\
\text { Estuco }\end{array}$ & $\begin{array}{l}\text { Relieve glifos } \\
\text { Pintura mural }\end{array}$ & $\begin{array}{l}\text { Plazas } \\
\text { Oratorios } \\
\text { Estelas } \\
\text { Altares monolíticos } \\
\text { Escalinatas } \\
\text { Jambas y dinteles } \\
\text { Palacios } \\
\text { Juegos de pelota } \\
\text { Observatorios astronómicos } \\
\text { Centros ceremoniales } \\
\text { Pirámides } \\
\text { Depósitos cisterna de agua } \\
\text { Templos }\end{array}$ & $\begin{array}{l}\text { Sacerdotes } \\
\text { Guerreros } \\
\text { Atuendos } \\
\text { Instrumentos musicales } \\
\text { Ceremonias } \\
\text { Sacrificios } \\
\text { Dios Quetzalcóatl } \\
\text { Jaguares } \\
\text { Serpientes } \\
\text { Chac Mool }\end{array}$ \\
\hline & 2. Escultura & $\begin{array}{l}\text { Piedra } \\
\text { Estuco } \\
\text { Madera } \\
\text { Barro } \\
\text { Basalto } \\
\text { Diorita } \\
\text { Piedra caliza }\end{array}$ & $\begin{array}{l}\text { Grabado } \\
\text { Bajo relieve }\end{array}$ & $\begin{array}{l}\text { Estelas } \\
\text { Bustos } \\
\text { Máscaras } \\
\text { Tablas } \\
\text { Paneles } \\
\text { Ídolos } \\
\text { Cascos } \\
\text { Calendario }\end{array}$ & $\begin{array}{l}\text { Retratos de sacerdotes } \\
\text { Pájaros } \\
\text { Animales varios } \\
\text { Dioses }\end{array}$ \\
\hline & 3. Pintura & & $\begin{array}{l}\text { Mural } \\
\text { Fresco }\end{array}$ & & Realista \\
\hline & 4. Cerámica & & $\begin{array}{l}\text { Espiral } \\
\text { Relieve }\end{array}$ & $\begin{array}{l}\text { Platos } \\
\text { Tazones } \\
\text { Jarras mortuorias }\end{array}$ & $\begin{array}{l}\text { Mortuorios } \\
\text { Motivos femeninos }\end{array}$ \\
\hline & 5. Tejido & $\begin{array}{l}\text { Algodón } \\
\text { Tintes naturales }\end{array}$ & & $\begin{array}{l}\text { Huipiles } \\
\text { Taparrabos } \\
\text { Capas } \\
\text { Cortinas }\end{array}$ & \\
\hline
\end{tabular}




\begin{tabular}{|c|c|c|c|c|c|}
\hline \multicolumn{6}{|c|}{ 2. AZTECAS } \\
\hline Área Cultural & Tipo de producción & Material & Técnica & Objetos - Artefactos & Motivos artísticos \\
\hline \multirow{5}{*}{ 2. Aztecas } & 1. Arquitectura & & & $\begin{array}{l}\text { Sistema de diques } \\
\text { Calzadas }\end{array}$ & \\
\hline & 2. Escultura & $\begin{array}{l}\text { Obsidiana } \\
\text { Cuarzo }\end{array}$ & & Calendario Azteca & $\begin{array}{l}\text { Diosa Coatlicue } \\
\text { Escenas agrícolas } \\
\text { Rituales religiosos } \\
\text { Costumbres }\end{array}$ \\
\hline & 3. Orfebrería & $\begin{array}{l}\text { Oro } \\
\text { Jade } \\
\text { Turquesa } \\
\text { Ámbar } \\
\text { Obsidiana } \\
\text { Esmeralda } \\
\end{array}$ & \begin{tabular}{|l} 
Batido \\
Realzado \\
Dorado \\
Chapeado \\
Forrado \\
Grabado \\
\end{tabular} & $\begin{array}{l}\text { Mosaicos } \\
\text { Máscaras } \\
\text { Cuchillos } \\
\text { Espejos } \\
\text { Navajas }\end{array}$ & $\begin{array}{l}\text { Animales } \\
\text { Felinos } \\
\text { Monos }\end{array}$ \\
\hline & 4. Arte Primario & Plumas & Bordado & $\begin{array}{l}\text { Escudos } \\
\text { Penachos } \\
\text { Mantos } \\
\text { Estandartes } \\
\text { Emblemas }\end{array}$ & \\
\hline & 5. Papel, escritura & Papel amate & Pictórica & Libros con relatos & \\
\hline
\end{tabular}




\begin{tabular}{|c|c|c|c|c|c|}
\hline \multicolumn{6}{|c|}{ 3. COSTA RICA } \\
\hline Área Cultural & Tipo de producción & Material & Técnica & Objetos o artefactos & Motivos artísticos \\
\hline $\begin{array}{c}\text { 3.1 Tradición mesoamericana } \\
\text { (influencia Maya, Tolteca } \\
\text { y Mixteca) }\end{array}$ & 1. Cerámica & $\begin{array}{l}\text { Engobe rojo } \\
\text { Engobe café } \\
\text { Engobe naranja }\end{array}$ & $\begin{array}{l}\text { Bicromo zonas } \\
\text { Lineal } \\
\text { Grabado } \\
\text { Pintura } \\
\text { Policromo }\end{array}$ & $\begin{array}{l}\text { Vasijas regulares } \\
\text { Vasijas cilíndricas } \\
\text { Vasijas antropomorfas } \\
\text { Metates trípodes } \\
\text { Vasija zoomorfa }\end{array}$ & $\begin{array}{l}\text { Líneas onduladas } \\
\text { Geometría sencilla } \\
\text { Motivos humanos } \\
\text { Motivos animales } \\
\text { Efigie jaguar } \\
\text { Tláloc } \\
\text { Xipe Totec } \\
\text { Quetzalcóatl } \\
\text { Motivos de códices }\end{array}$ \\
\hline $\begin{array}{l}\text { 3.2 Tradición sudamericana } \\
\text { (influencia Inca) }\end{array}$ & 1. Metalurgia & $\begin{array}{l}\text { Oro } \\
\text { Plata } \\
\text { Cobre } \\
\text { Bronce }\end{array}$ & $\begin{array}{l}\text { Extracción } \\
\text { Modelado } \\
\text { Martillado } \\
\text { Soldadura } \\
\text { Unión con pernos }\end{array}$ & $\begin{array}{l}\text { Vasos } \\
\text { Figuras femeninas } \\
\text { Penachos } \\
\text { Pectorales } \\
\text { Colgantes } \\
\text { Cuchillos } \\
\text { Instrumentos quirúrgicos } \\
\text { Platos } \\
\text { Vajilla }\end{array}$ & $\begin{array}{l}\text { Serpientes } \\
\text { Arañas } \\
\text { Lagartos }\end{array}$ \\
\hline
\end{tabular}

Fuente: Elaboración propia. 
La autora denomina estas expresiones como manifestaciones artísticas, pese a relacionarlas con lo religioso o cultural en las descripciones. Como se ha indicado, Aguilar (1972) introdujo la categoría de lo artístico en la producción orfebre precolombina, la cual es retomada, también, en la tesis de Corrales (1974), con énfasis en lo decorativo y representacional de las piezas. Por su parte, Tello (1977) incorpora lo artístico con una dirección hacia el culto y lo religioso, como elementos fundamentales de la necesidad plástica: "el artista no crea la imagen de los dioses como adorno, aquí el arte está sometido a fines religiosos" (Tello, 1977, p. 10).

La tesis, de carácter ensayístico, no enfatiza en la identificación de aspectos formales o materiales, como si se estableció en los trabajos anteriores. Se refiere a la orfebrería como trabajo en metales o metalurgia y utiliza ambos términos, indistintamente. Sobre esta producción no construye grupos de objetos, descripciones técnicas ni materiales detalladas. Más bien, hace mención de esos aspectos en forma breve, mientras enfatiza en el aspecto religioso. La producción orfebre como manifestación artística-religiosa es el enfoque fundamental del que parte la autora al afirmar que: "todo el trabajo artístico del indio [sic] es un mudo, pero elocuente esfuerzo por rendir tributo a sus dioses" (Tello, 1977, p.71). Este enfoque cultural, el cual se traduce en una nueva lectura de los objetos, evidencia una preocupación mayor por establecer relaciones entre objetos y culto que por atender las cualidades formales, técnicas o descriptivas, aunque no las abandona.

La autora utiliza un nuevo modelo para las zonas culturales precolombinas de Costa Rica. Es la única que se desmarca de la división tradicional de tres poblaciones indígenas y sus zonas geográficas. Está basado en dos grandes grupos de influencia cultural: 1) Zona de tradición mesoamericana, que comprende el noroeste de Costa Rica, con influencia maya, tolteca y mixteca. 2) Zona de tradición sudamericana, el cual comprende el Valle Central, las llanuras del Norte, la Vertiente Atlántica y el Pacífico Sur. Esta división le permite acercar la producción costarricense a los otros grupos culturales que analiza en su tesis. Su forma de abordar la división cultural precolombina constituye un aporte en términos de conocimiento, al omitir los dos modelos anteriores. Así, denota el avance de los estudios arqueológicos en Costa Rica, para ese momento.

Durante la década de 1970, los arqueólogos se proponen entender la historia latinoamericana en su integralidad y comprender los procesos de formación sociohistórica de las poblaciones antiguas, previos a la colonización europea. Así, entran en el panorama otros aspectos para la interpretación de los objetos, más allá de su descripción material. Se trata de reconstruir o interpretar los modos de vida teniendo en cuenta su dimensión social. Más allá de ver el artefacto, se trata de ver a la persona detrás del artefacto. Bajo esta premisa, utilizar el pasado para entender el presente. Este pensamiento se concreta en va- 
Imagen 4. BCCR- 523. Colgante en forma de rana. Pacífico Sur / 700-1500 d.C.

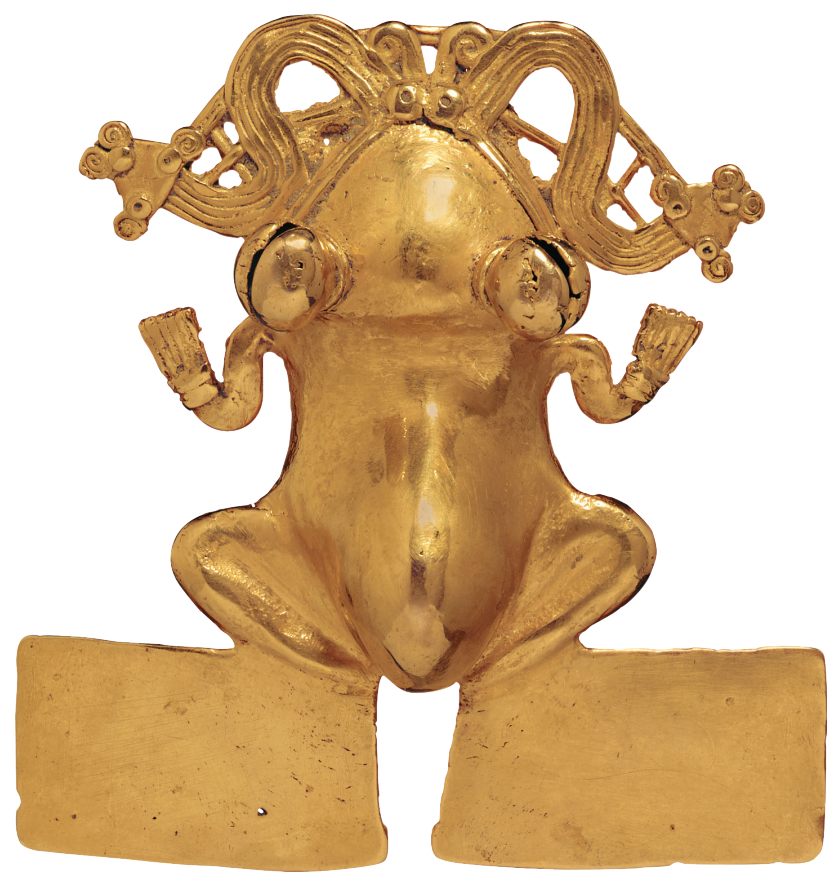

Fuente: Colección Museos del Banco Central de Costa Rica (Fotografía Mike \& Corinna Blum). rios escritos de la época, que inciden con fuerza en la arqueología social. Este concepto evoluciona en los años posteriores, lo que añade otras categorías de análisis en la arqueología: formación económico social, modo de producción, modo de vida, modo de trabajo y cultura (Vargas \& Sanoja, 1995, p. 151). Esta nueva forma de comprender los objetos antiguos marcó una clara diferencia en los análisis realizados durante la década de los años 1970 (Imagen 4).

\section{Conclusiones}

Un periodo de veinticuatro años separa la primera de la última tesis incluidas en el presente estudio. Este tiempo enmarca una serie de eventos relevantes en el devenir de los estudios sobre la orfebrería precolombina en las tesis de la EAP de la UCR. Las diversas perspectivas de los autores han sido referenciadas en el estudio. Por una parte, el dominio científico de la Arqueología, cuyos elementos de estructura y documentación mantienen una importante influencia. Por otra parte, el giro iconográfico con el cual los elementos plásticos introducen un aporte al análisis de la orfebrería, donde los objetos pasan de ser objetos arqueológicos de museo a objetos con fines decorativos y portadores de contenido simbólico. Pero, además, vinculados a su entorno y cultura.

Los análisis que establecen las autoras de las dos últimas tesis, Corrales (1975) y Tello (1977) muestran una observación ampliada de los objetos, al asociar la representación con aspectos culturales vinculados, principalmente, a lo religioso. Desde la tesis de Revollar (1968) ya se percibía la necesidad de superar el análisis de los aspectos meramente visibles. Razón por la que el autor incluía la categoría de los simbólico. Por su parte, Madriz (1974) instaura el aspecto social como una categoría inherente a los objetos que, posteriormente, se fusiona con lo artístico. Las categorías de análisis para la orfebrería extraídas de las investigaciones son: 
1. Arqueológica: modelo histórico, aspectos formales, materiales, técnica y tipología de objetos.

2. Histórico: hechos relevantes, cronología, región, contexto geográfico y temporal.

3. Artístico: función decorativa, motivos, representaciones, estilo y diseño.

4. Social: función de los objetos en la vida cotidiana.

5. Cultural: función religiosa vinculada a lo representacional.

Además, es posible identificar los cambios en el tratamiento del tema y la relevancia de los acontecimientos contextuales que, en materia arqueológica y artística, se suscitaron durante este periodo. El auge de las excavaciones, el coleccionismo y la construcción de identidad jugaron un papel determinante en el interés por la temática y el estudio de los objetos. Este análisis evidencia que, tanto el auge de la Arqueología como el inicio de los cursos de orfebrería en la EAP propiciaron un avance en el conocimiento de las técnicas y materiales utilizados en la orfebrería precolombina. Es claro que los autores investigaban mucho más sobre los procesos de fabricación, por lo que otras técnicas, materiales y tipologías de objetos se fueron sumando de una tesis a otra, con el paso del tiempo. Tal y como se mencionó, la base arqueológica es fundamental y está presente en todas las tesis. Desde el inicio, los autores se apegaron a los modelos históricos vigentes para sustentar sus análisis y consideraron el material, la técnica y los datos históricos en las descripciones de los objetos. La publicación de Aguilar (1972) marcó la pauta sobre la catalogación de la orfebrería precolombina. Así, los investigadores posteriores, al tomar este texto como base, realizaron diversos aportes en el análisis de la orfebrería, desde el punto de vista artístico.

El término orfebrería es utilizado, por primera vez, en la tesis de Revollar (1968). En estudios previos los autores nombraron esta producción como metales, metalurgia o trabajos en metal. Aunque, actualmente cualquiera de ellos puede ser utilizado, merece la pena destacar la influencia del estudio de catalogación que realizó Aguilar (1972) para la colección de oro del BCCR, donde se encontró esta denominación. También, introdujo la valoración de estas piezas como joyas o joyería, término que se identificó en estudios posteriores al suyo, hasta entenderse como joyería prehispánica, en Tello (1977). Además, se logró determinar cómo, a través del tiempo, la figura del artesano indígena que trabajó en la fabricación de objetos de metal pasó por varias denominaciones: indígena, orfebre indígena, orfebre y artista o artífice.

En la década de 1970, la EAP se perfilaba como una institución pionera en la enseñanza de la orfebrería. Se realizaron esfuerzos por lograr la profesionalización del oficio, como la creación de la Licenciatura en Orfebrería y la adquisición de un taller completo y equipado. Sin embargo, el programa de especialidad no se concretó, a pesar de que el plan fue aprobado hace muchos años, según afirma Herberth Zamora. El primer curso libre 
fue impartido por un profesor norteamericano. Más tarde, otros docentes obtuvieron especialidades en orfebrería gracias a convenios con universidades en los Estados Unidos. Su objetivo era regresar al país e impartir los cursos del programa de Licenciatura en Orfebrería, que no logró consolidarse. En los años siguientes, la orfebrería se convirtió en un curso introductorio y, luego, complementario. En la actualidad, se imparte como curso optativo.

El señor Herberth Zamora afirma que, bajo la dirección de Eric Hidalgo (2014-2018), se intentó revivir la especialidad, pero, el proyecto no fue factible por situaciones de espacio y presupuesto. Se analizó la posibilidad de enviar estudiantes a universidades en el extranjero para formar especialistas titulados y fortalecer el cuerpo docente, apreciación que también compartió Luis Paulino Delgado. Ambos especialistas coinciden en la necesidad de recuperar la orfebrería. Zamora afirma que la tendencia de la EAP, en la actualidad, se dirige al fortalecimiento de las artes integradas, con énfasis en lo conceptual sobre el oficio, lo que relegaría la orfebrería a un curso complementario. Por su parte, Luis Paulino Delgado considera relevante la profesionalización de la orfebrería, la cual solo sería posible a través de un plan a mediano plazo, que contemple el fortalecimiento del cuerpo docente mediante titulaciones en el extranjero y la inversión en infraestructura. Pero que, sobre todo, requiere de liderazgo, trabajo y compromiso.

Hasta aquí es posible constatar el desarrollo de las tesis sobre orfebrería precolombina que, como lo muestra el estudio, ha sido una especialidad poco explorada en la EAP de la UCR. Sin embargo, las diferencias entre las tesis y sus aportes evidencian la correspondencia de la investigación con respecto al contexto espacio-temporal y el uso de la teoría disponible. Entre los años 1953 a 1977 fueron presentadas apenas quince tesis sobre arte precolombino. De estas, cinco incluyen la producción orfebre y solo una plantea el estudio de la orfebrería con especificidad, un descubrimiento que amerita reflexión y problematización. La primera gran interrogante se sitúa en la poca exploración académica que se ha generado sobre orfebrería precolombina, en la EAP.

La colección de arte precolombino del Museo de Oro es una de las más importantes de América Latina y del mundo. Actualmente, es objeto de estudio desde otras especialidades en busca de precisión, respuestas y descubrimientos sobre el pasado costarricense. Está conformada por un total de 3567 piezas, de las cuales 1586 corresponden a orfebrería. El tesoro data del 300-400 a.C. y contiene "colgantes, cuentas, cascabeles, brazaletes, orejeras, discos, diademas, instrumentos y herramientas, pectorales, láminas, pepitas, metates y figurillas varias" (Molina, 2017, p. 10). Con la inauguración de la Plaza de la Cultura, en San José (1980 -1982) "se trasladó la colección del Museo de Oro Precolombino Álvaro Vargas Echeverría a las nuevas instalaciones” (Fernández, Triana \& Chacón, 2010, p. 8). Desde entonces, el oro precolombino de Costa Rica es resguardado y visitado 
por los costarricenses en este museo. Cabe destacar que, otros objetos de orfebrería se encuentran también resguardados en el Museo Nacional de Costa Rica. La iconografía mostrada en esta producción manifiesta aspectos de la vida cotidiana de los indígenas precolombinos y su cosmovisión, sobre lo cual, queda aún mucho más por descubrir.

\section{Referencias}

Aguilar, C. (1972). Colección de objetos indígenas de oro del Banco Central. Editorial de la Universidad de Costa Rica. San José: Costa Rica.

Coladán, E. \& Corrales, F. (2000). Floreros trípodes y metates de panel colgante: La arqueología y la enseñanza de los Estudios Sociales. Perspectivas, 3(1 y 2). Recuperado de: http://www.revistas.una.ac.cr/index.php/perspectivas/article/view/3850

Corrales, C. (1975). Representaciones y estilos decorativos de la metalurgia costarricense. (Tesis Licenciatura). Universidad de Costa Rica. San José, Costa Rica.

Corrales, F. (2003). La investigación arqueológica en Costa Rica al finalizar el siglo XX y empezar el XXI. En M. Samper, I. Molina, F. Enríquez \& J. Cerdas (editores), Entre dos siglos. La investigación histórica costarricense. Alajuela, Costa Rica: Museo Histórico Cultural Juan Santamaría. 25-46

Fernández, P., Triana, M. \& Chacón, B. (2010). Banco Central de Costa Rica 60 Aniversario: 1950 - 2010: Preservando nuestro Patrimonio Económico y Cultural. San José, Costa Rica: Editorial Fundación Museos del Banco Central.

Ferrero, L. (2003). Costa Rica Precolombina. San José, Costa Rica: Editorial Costa Rica.

Gómez, L. (1984). Propuesta de creación de un centro didáctico y taller de artes plásticas para el Museo de Jade del Instituto Nacional de Seguros. (Tesis para optar al grado en Licenciatura en Artes Plásticas). Universidad de Costa Rica. San José, Costa Rica.

Huertas, M. (1953)._Arte Pre-Colombino en Costa Rica. (Tesis para optar al grado de Licenciatura en Artes Plásticas). Universidad de Costa Rica. San José, Costa Rica.

Lorandi, A. (2012). ¿Etnohistoria, Antropología Histórica o simplemente Historia? Memoria Americana. Cuadernos de Etnohistoria, 20(1). Recuperado de: http://ppct. caicyt.gov.ar/index.php/memoria-americana/article/view/1960

Madriz, V. (1974)._Arte Precolombino en Mesoamérica. Arte en Perú y Colombia culturas precolombinas, Paul Gauguin. (Tesis para optar al grado de Licenciatura en Artes Plásticas). Universidad de Costa Rica, San José, Costa Rica. 
Molina, P. (2017). Piezas extraordinarias del Museo del Oro Precolombino de Costa Rica. San José, Costa Rica: Fundación Museos del Banco Central.

Obando, E (2008). Banco Central de Costa Rica: su historia y su gente 1950-2002. San José, Costa Rica: Banco Central de Costa Rica.

Revollar, R. (1968). Cuatro conferencias sobre Historia del Arte. (Tesis para optar al grado de Licenciatura en Artes Plásticas). Universidad de Costa Rica. San José, Costa Rica.

Rojas, G. (2003). Arte costarricense: un siglo. San José, Costa Rica: Editorial Costa Rica.

Solano, S. (2014). Historiografía del Arte Costarricense 1960-2014: Un aporte al análisis de sus voces, temáticas y perspectivas. Estudios, (29), 389-400. https://doi. org/10.15517/re.v0i29.17826

Solórzano, J. (2011). El arte precolombino en el quehacer académico costarricense: trabajos finales de graduación (1953-2005). ISTMO. Revista de estudios literarios y culturales centroamericanos, 22. Recuperado de: http://istmo.denison.edu/n22/ proyectos/01.html

Tello, S. (1975). Arte indígena americano. (Tesis para optar al grado de Licenciatura en Artes Plásticas). Universidad de Costa Rica. San José, Costa Rica.

Vargas, I. \& Sanoja, M. (1995). La arqueología como ciencia social y su expresión en América Latina. Revista de Arqueología Americana, (9), 141-163. Recuperado de http://www.jstor.org.ezproxy.sibdi.ucr.ac.cr:2048/stable/27768357 